\title{
A continued need for simulation facilities, technologies, and resources in Canadian urology training
}

\section{Elspeth M. McDougall, MD, FRCSC, MHPE}

Department of Urologic Sciences, University of British Columbia, Vancouver, BC, Canada

Cite as: McDougall EM. A continued need for simulation facilities, technologies, and resources in Canadian urology training. Can Urol Assoc J 2020;14(10):328-9. http://dx.doi.org/10.5489/ cuaj.6923

See related article on page 322

$\mathrm{T}$ he training of a competent urologist is a complex multidimensional process. As in any learning process, educational activities must address objectives in the cognitive, affective, and psychomotor domains. ${ }^{1}$ Simulation is but one teaching strategy and should be integrated into a well-developed training curriculum. It is critical that educators understand the benefits and advantages of simulationbased training over other teaching strategies and implement such methods when and where appropriate. ${ }^{2}$

High-fidelity and expensive simulation platforms, such as cadavers and virtual reality simulators, are not always necessary for effective trainee learning. More inexperienced learners, such as junior residents, can have very effective simulated learning on low-fidelity and material models, which is probably reflected in their positive assessment of their simulation experience in the survey-based study by Lobo et al in this issue CUAJ. ${ }^{3}$ Senior residents really need the higher fidelity platforms to improve their more advanced and specific surgical skills learning needs. However, the observation that residents are not using the skills training labs because the practice is not mandatory and they are too busy reflects the importance of making simulation-based practice an integral portion of the curriculum. This requires building time within the resident educational activities on a regular basis to accommodate this formal practice.

Simulation is best implemented to reinforce a principle of learning or to practice a specific skill, such as suturing and knot-tying or safe patient handover. The benefits of simulation training are as follows:

- Builds on existing knowledge base

- Addresses the learner's needs in a practical and clinically relevant way that has immediate application

- Permits repetitive practice of skills to an expertdefined, prescribed level of proficiency in a risk-free environment
- Ideally provides immediate feedback from experts and gives trainee a chance to complete the task using knowledge of errors or complications experienced during the practice session

The simulation activity should have clearly delineated performance expectations that are defined by the experts and can be objectively measured. The debriefing step at the conclusion of a simulation is crucial to clarify lessons learned from the experience. ${ }^{4}$ This requires educators skilled in the debriefing process to ensure a constructive review that allows participants to explore, analyze, and synthesize their actions and thought processes, emotional states, and other information from the activity and to improve performance in clinical practice. Participant engagement is a hallmark of strong debriefings because it leads to deeper levels of understanding and increases the likelihood of the knowledge gained being used in a clinical setting. ${ }^{5}$

It is reassuring that in their study, Lobo et al determined that $92 \%$ of Canadian urology residency programs (CURPs) currently have access to a surgical skills lab. Unfortunately, the percentage of CURPs that have urology-specific SSLT has increased only marginally, from $59 \%$ to $69 \%$, in the past eight years. It is not surprising that the main barriers to the development and implementation of SSLT include lack of protected time for faculty to develop and implement these sessions, lack of funding, and lack of protected academic time for residents to participate, as these have persisted over the past two decades. As has been previously delineated, a significant responsibility for these shortcomings lies with the current certification process from the Royal College of Physicians and Surgeons of Canada, which does not include a formal evaluation of technical skills. ${ }^{6}$ With clear guidelines for competency in specific required technical skills for urologic surgeons, nationwide training curricula could be developed to provide appropriate simulation-based learning in these domains and establish expert-determined proficiency levels for each of these skills. This would then assist training programs to determine exactly what the SSLT needs to provide and help faculty develop and implement these teaching strategies. It would also assist in determining a realistic budget for SSLTs and more effective budget parameters by which to seek grant and institutional funding. 
Recently, due to the complexity of modern patient care, simulation-based training has been used to provide errorresponse and group training for the high-reliability teams working in environments such as the operating room. ${ }^{5}$ Much can be learned by the high-reliability team experiencing errors and practicing responses in their daily work environment. As in the aviation industry, where team simulation training is used to ensure passenger safety, the healthcare sector can improve medical safety and efficiency by having entire healthcare teams take part in a simulation-based practice and debriefing process. It will be most beneficial for urology trainees to begin learning these important communication skills early in their clinical experience and this can be facilitated in a simulated-based learning environment.

Given that good simulation-based practice addresses training requirements for urologic trainees in a practical and clinically relevant way, the need for simulation facilities, technologies, and resources in Canada can be expected to continue.

\section{References}

1. Kern DE, Thomas PA, Hughes MT. Curriculum development for medical education: A six-step approach. 2nd ed. Baltimore: Johns Hopkins University Press; 2009.

2. Ericsson KA. Deliberate practice and the acquistion and maintenance of expertperformance in medicine and related domains. Acad Med 2004;79:570-81. https://doi.org/10.1097/00001888-20041000100022

3. Lobo AM, Doucette $S$, Lantz Powers AG. Stakeholder perspectives and status of surgical simulation and skills training in urology residency programs in Canada. Can Urol Assoc J 2020;14:322-7. http://dx.doi.org/10.5489/cuai.6286

4. Fanning RM, Gaba DM. The role of debriefing in simulation-based learning. Simul Healthcare 2007;2:11525. https://doi.org/10.1097/SlH.0b013e3180315539

5. Moorthy K, Munz Y, Adams S, et al. A human factors analysis of technical and team skills among surgical trainees during procedural simulations in a simulated operating theatre. Ann Surg 2005;242:631-9. hitps://doi.org/10.1097/01.sla.0000186298.79308.a8

6. Nayan M, Houle AM, MCDougall E, et al. Establishing milestones in urology training: A survey of the Canadian Academy of Urological Surgeons. Can Urol Assoc J 2012;6:168-74. https://doi.org/10.5489/ cuaj.11248

Correspondence: Dr. Elspeth M. McDougall, Department of Urologic Sciences, University of British Columbia, Vancouver, BC, Canada; Elspeth.m@ubc.ca

Competing interests: The author reports no competing personal or financial interests related to this work.

\section{UROLOGY UPDATE 2020}

\section{Wednesday, November 11, $2020 \cdot 7: 00-9: 30$ pm EDT} Thursday, November 12, 2020 • 7:00-9:30pm EDT

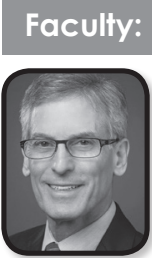

Co-Chair: Girish Kulkarni Committee: Sidney Radomski, Kenneth Pace

Chair:

\section{Invited Faculty:}

Peter Black

Vancouver, BC

Sender Herschorn

Nathan Lawrentschuk

Melbourne, Australia

Daniel Barocas

Nashville, TN

Victor Nitti

Los Angeles, CA

University of Toronto Faculty - Urology

Lesley Carr

Dean Elterman

Monica Farcas

Neil Fleshner

Robert Hamilton

Sender Herschorn

Michael A.S. Jewett

Laurence Klotz
Jason Lee

Robert Nam

Michael Ordon

Kenneth Pace

Nathan Perlis

Sidney Radomski

Alexandre Zlotta

Jerome Green

\section{VIRTUAL MEETING}

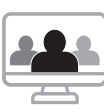

TOPICS:

New AUA Microhematuria Guidelines

BPH Technologies

Stones

Female SUI

Refractory Overactive Bladder

Prostate Cancer

Bladder Cancer

Kidney Cancer 